\title{
Rapid Determination of Biochar Energy Quality Based on Visible and Near-infrared Spectroscopy $(400-1000 \mathrm{~nm})$
}

\author{
Hai-Qing YANG ${ }^{1}$, a, Geng-Xin GUO'1 and Jian-Bing $\mathrm{Jl}^{2}$ \\ ${ }^{1}$ College of Information Engineering, Zhejiang University of Technology, 310023 Hangzhou, China \\ 2Zhejiang Provincal Key Laboratory of Biofuel, Zhejiang University of Technology, 310014 Hangzhou, China \\ a Corresponding author: yanghq@zjut.edu.cn
}

\begin{abstract}
Rapid determination of biochar energy quality is fundamental for the purpose of biomass efficient utilization. In this work, visible and near-infrared spectroscopy was used to measure ash, volatile matter, fixed carbon content and calorific value of biochar samples produced at different pyrolysis temperatures from agricultural biomass feedstocks. Biochar samples were detected by a USB4000 spectrometer with 400-1000nm reflectance spectra recorded for investigation. The spectra were transformed by Savitzky-Golay smoothing followed by baseline offset correction (BOC). The BOC-transformed spectra of calibration set were subjected to a partial least squares regression (PLSR) algorithm for obtaining a PLSR calibration model for each biochar property. Prediction result shows that the PLSR models developed for 400-1000nm spectra achieve good prediction performance with coefficient of determination $\left(\mathrm{R}^{2}\right)$ of $0.85,0.86,0.87$ and residual prediction deviation (RPD) of 2.61, 2.64, 2.85 for ash, volatile matter and fixed carbon content, respectively. For the prediction of biochar calorific value, the PLSR model developed for 400-780nm spectra performs better with $\mathrm{R}^{2}$ of 0.82 and RPD of 2.51 compared with the $400-1000 \mathrm{~nm}$ spectra. It is suggested that biochar energy quality can be rapidly measured with acceptable accuracy based on a 400-1000nm spectrum which can be obtained by a low-cost spectrometer.
\end{abstract}

\section{Introduction}

Biochar is a product of thermal degradation of organic materials in the absence of air (pyrolysis). Except for being an excellent material for improving soil fertility as well as ecosystem services such as mitigating climate change by sequester carbon; biochar has also been utilized for energy purpose [1]. Conversion of agricultural wastes into biochar not only can save natural resource but also protect environment. Biochar energy quality is mainly influenced by its feedstock type as well as pyrolysis conditions. However, it is very cost- and time-consuming to determinate biochar energy quality, for example, to measure calorific value conventionally should be conducted by physic-chemical means in laboratory. Thus, it is necessary to develop an alternative for rapid determination of biochar energy quality cheaply and conveniently.

Recently, visible and near-infrared reflectance spectroscopy (vis-NIR) has received increasing attention because it is characteristic of rapid measurement, ease to use and absence of agents. This technology has been used for the analysis of biomass feedstock properties. Sanderson et al. used the technology to determine chemical compositions of several woody and herbaceous feedstocks', such as ethanol extractives, ash and lignin [2]. Based on an OSC-treated kernel PLSR method,
Labbé et al. achieved highest coefficient of correlation and lowest root-mean square of error (RMSE) for the prediction of ash and char content of three types of woody biomass (red oak, yellow poplar, hickory) and three herbaceous biomasses (switch grass, corn Stover, sugarcane bagasse)[3]. Allison et al. measured several key compositional parameters (alkali index, nitrogen, carbon and ash contents) in two species of energy grass (switch grass and reed canary grass) by Fourier transform infrared spectroscopy [4]. Nkansah et al. used the spectroscopy as a process analysis tool for the rapid characterization of physical (bulk density) and chemical properties (insoluble and acid-soluble lignin, extractives, and ash) of yellow-poplar [5]. Fagan et al. predicted the moisture, calorific value, ash and carbon content of two dedicated bio-energy crops (Miscanthus and Short Rotational Coppice Willow)[6]. All the above-mentioned reports focused on the measurement of biomass feedstock properties. To our knowledge, however, there is no report on using the vis-NIR spectroscopy to predict biochar energy quality.

As known, weak overtones and combinations of the middle-infrared fundamental vibrations $(2500-25000 \mathrm{~nm}$ or $4000-400 \mathrm{~cm}-1)$ due to the stretching and bending of $\mathrm{N}-\mathrm{H}, \quad \mathrm{O}-\mathrm{H}$ and $\mathrm{C}-\mathrm{H}$ groups dominate the NIR $(780 \sim 2500 \mathrm{~nm})$ and electronic transitions in the visible $(350 \sim 780 \mathrm{~nm})$ portions of the electromagnetic (EM) 
spectrum[7]. It might be probable to use the vis-NIR spectroscopy for the characterization of biochar energy quality, although using middle-infrared wavelengths range may produce higher performance than vis-NIR range, as shown in other reports $[7,8]$.

This study aims to explore the potential of using a visNIR spectrum of $400-1000 \mathrm{~nm}$ to determinate biochar energy quality, namely, to measure ash, volatile matter, fixed-carbon content and calorific value of biochar samples produced at different pyrolysis temperatures from three selected types of agricultural biomass feed stocks. Calibration models were also developed for different wavelengths range with the purpose of model optimization.

\section{Materials and Methods}

\subsection{Biochar Samples Preparation}

Pine and cedar wood chips were collected from a local timber production factory. Cotton stalk was gathered from a local farmland. The biomass wastes were left outdoors for air-drying one month. The dried materials were broken by machine and further ground to pass through a 40-mesh screen. Biochar was produced via the pyrolysis of the raw biomass at various temperatures under oxygen-limited conditions, which allowed the materials to be charred rather than combusted. Briefly, the biomass was placed in a ceramic pot covered with a fitting lid, and underwent pyrolysis in a muffle furnace with peak temperatures of 300, 350, 400, 450, 500, 550 and $600^{\circ} \mathrm{C}$ for $2 \mathrm{~h}$. For each temperature, four biochar samples were prepared for cedar and pine wood and eight samples for cotton stalk. A total of 112 biochar samples were prepared with 28, 28 and 56 samples for cedar wood, pine wood and cotton stalk biomass, respectively.

From each sample, $4 \sim 5 \mathrm{~g}$ was used for laboratory measurement of ash(wt.\%), volatile matter( $V M$, wt.\%) and calorific value $(C V, \mathrm{MJ} / \mathrm{kg})$. The ash and $V M$ were measured according to the criteria of NY/T1881.42010(China) and the $C V$ according to the standard of GB/T 213-2003(China). Measurements were conducted on the dry base. Fixed carbon content $(F C$, wt.\%) was calculated by

$F C(w t . \%)=1-A \operatorname{sh}(w t . \%)-V M(w t . \%)$.

\subsection{Spectral Data Acquisition}

A subsample of about $5 \mathrm{~g}$ was loaded into a static ring cup and measured with a USB4000 spectrometer (Ocean Optics, USA) equipped with an optic fiber for light transmission. The light source was a halogen bulb of $3000 \mathrm{~K}$. The spectrometer provided spectra with 3648 wavelengths from $345.61 \mathrm{~nm}$ to $1047.63 \mathrm{~nm}$. Due to the noise at both ends, only the range of 400-1000nm was remained for further investigation. All spectra were recorded in diffuse reflectance mode. Before sample spectral scanning, ten reference scans were taken on a ceramic standard supplied with the spectrometer. Twenty photometric scans were conducted and averaged for each sample.

\subsection{Spectral Data Processing Methods}

The spectra were processed with the Unscramble X10.1 (CAMO, Oslo, Norway). The spectra were randomly divided into two separate set for calibration (2/3) and prediction (1/3). Several spectral pre-processing algorithms including Savitzky-Golay smoothing, multiplicative scatter correction, standard normal variate, de-trending and derivatives were investigated but were not useful for model improvement. The only beneficial spectrum transformation was baseline offset correction (BOC), conducted by

$$
f(x)=x-\min (X)
$$

where $x$ is a variable and $X$ denotes all selected variables. The value of the lowest point in a spectrum is subtracted from all the variables. BOC can eliminate light-path difference caused by rough sample surface.

The BOC-transformed spectra in the calibration set were subjected to a partial least squares regression (PLSR) to build a calibration model for each bio char property. All PLSR models were conducted with leave-one-out cross-validation and the number of latent variables (LVs) used in the PLSR models was determined by minimizing the predicted residual error sum of squares (PRESS). The performance of PLSR models was evaluated for the prediction set.

PLSR model performance was evaluated by the root mean squared error (RMSE) of calibration (RMSEC), cross-validation (RMSECV) and prediction (RMSEP). The formula of $R M S E$ is

$$
R M S E=\sqrt{\frac{\sum\left(X_{m}-X_{p}\right)^{2}}{N}}
$$

where $X_{m}$ is the reference value, $X_{p}$ is the PLSpredicted value, and $N$ is the number of samples used for calibration or prediction. PLSR models were also evaluated by the residual predictive deviation (RPD), which is the ratio of standard deviation of reference values of the prediction set to the RMSEP. The criteria adopted for $R P D$ classification [8] was that an $R P D$ of 1.5 2.0 indicates a possibility of distinguishing between large and small values, while a value of 2.0 2.5 makes approximate quantitative predictions possible. Prediction is classified as good if $R P D$ of $2.5 \sim 3.0$. We also evaluated the model performance by means of the coefficient of determination ( $R^{2}$ ) for prediction. In fact, $R^{2}$ indicates the percentage of the variance in the $Y$ variable that is accounted for by the $X$ variable [9]. $R^{2}$ Of $0.66 \sim 0.81$ indicates approximate quantitative prediction, whereas a value of $0.82 \sim 0.90$ reveals good prediction. Generally, a good model prediction would have large values of $R^{2}$ and $R P D$, and small values of RMSE. 


\section{Results and Discussion}

\subsection{Characteristics of Biochar Reflectance spectra}

Figure 1 shows the changes of BOC-transformed bio char reflectance with spectral wavelengths from $400 \mathrm{~nm}$ to $1000 \mathrm{~nm}$. The spectra present low reflectance in visible range of $450-650 \mathrm{~nm}$, which corresponds to the black color of bio char. However, the reflectance became stronger and stronger in the near infrared range of above $780 \mathrm{~nm}$.

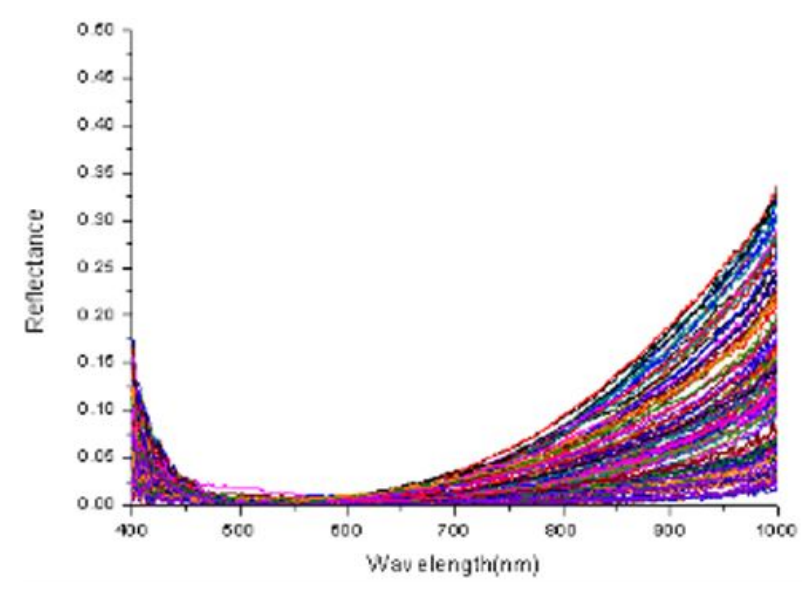

Figure 1. Reflectance spectra of all biochar samples

\subsection{PLSR Determination of Biochar Energy Quality}

In order to investigate the contribution of different range of wavelengths to the performance of PLSR models calibrated for biochar energy quality, the spectrometerrecorded vis-NIR spectra of $400-1000 \mathrm{~nm}$ were divided into two ranges, visible range of $400-780 \mathrm{~nm}$ and shortwave near-infrared range of $780-1000 \mathrm{~nm}$. Thus, three groups of PLSR models were established respectively for the vis-NIR range of $400-1000 \mathrm{~nm}$, the vis range of 400 $780 \mathrm{~nm}$ and the NIR range of $780-1000 \mathrm{~nm}$. The different groups of PLSR models were compared with each others in terms of the values of $R^{2}$ and RPD of calibration and prediction sets.

The PLSR models calibrating the wavelengths of 400$1000 \mathrm{~nm}$ to biochar energy properties achieved good performance for calibration and prediction (Table 1). For example, the PLSR model for ash content produced $R^{2}$ of 0.93 and $R M S E$ of $1.0 \%$ for calibration, and $R^{2}$ of 0.85 , $R M S E$ of $1.3 \%$, and $R P D$ of 2.61 for prediction. The PLSR models for volatile matter and fixed carbon contents were develop with 3 or 4 latent variables and achieved similar performance with $R^{2}$ of $0.89-0.91$ for calibration, and $R^{2}$ of $0.86-0.87$ for prediction. By comparison, the PLSR model for biochar calorific value produced middle-level accuracy with $R^{2}$ of 0.80 and RMSE of $0.56 \mathrm{MJ} / \mathrm{kg}$ for calibration, and $R^{2}$ of 0.80 , $R M S E$ of $0.60 \mathrm{MJ} / \mathrm{kg}$, and $R P D$ of 2.27 for prediction.
Table 1. Performance of PLSR models developed for 400$1000 \mathrm{~nm}$ spectra

\begin{tabular}{lllllll}
\hline \multirow{2}{*}{$\begin{array}{l}\text { Biochar } \\
\text { energy } \\
\text { property }\end{array}$} & \multirow{2}{*}{$\begin{array}{l}\text { PLSR } \\
\text { LVs }\end{array}$} & \multicolumn{3}{l}{$\begin{array}{l}\text { Calibration } \\
\text { set }\end{array}$} & \multicolumn{4}{c}{ Prediction set } \\
\cline { 3 - 7 } & & $R^{2}$ & $R M S E$ & $R^{2}$ & $R M S E$ & $R P D$ \\
\hline $\begin{array}{c}\text { Ash } \\
\text { (wt.\%) }\end{array}$ & 5 & 0.93 & 1.0 & 0.85 & 1.3 & 2.61 \\
\hline $\begin{array}{c}\text { VM } \\
\text { (wt.\%) }\end{array}$ & 3 & 0.89 & 2.1 & 0.86 & 2.5 & 2.64 \\
\hline $\begin{array}{c}\text { FC } \\
\text { (wt.\%) }\end{array}$ & 4 & 0.91 & 1.6 & 0.87 & 2.0 & 2.85 \\
\hline $\begin{array}{c}\text { CV } \\
(\mathrm{MJ} / \mathrm{kg})\end{array}$ & 4 & 0.80 & 0.56 & 0.80 & 0.60 & 2.27 \\
\hline
\end{tabular}

By comparison, the PLSR models calibrating the visible range of $400-780 \mathrm{~nm}$ to biochar energy properties present different performance(Table 2). For example, the PLSR model for ash content performs worse with $R^{2}$ of $0.76, R M S E$ of $1.7 \%$, and $R P D$ of 2.06 for prediction. The PLSR models for volatile matter and fixed carbon contents which were developed with more latent variables cannot produce good performance for calibration and prediction as well. The only improvement can be found in the performance of the PLSR model developed for biochar calorific value based on the visible range of $400-780 \mathrm{~nm}$. The PLSR model achieves $R^{2}$ of $0.84, R M S E$ of $0.52 \mathrm{MJ} / \mathrm{kg}$ for calibration, and $R^{2}$ of 0.82 , $R M S E$ of $0.54 \mathrm{MJ} / \mathrm{kg}$, and $R P D$ of 2.51 for prediction.

Table 2. Performance of PLSR models developed for 400$780 \mathrm{~nm}$ spectra

\begin{tabular}{|c|c|c|c|c|c|c|}
\hline \multirow{2}{*}{$\begin{array}{l}\text { Biochar } \\
\text { energy } \\
\text { property }\end{array}$} & \multirow{2}{*}{$\begin{array}{l}\text { PLSR } \\
\text { LVs }\end{array}$} & \multicolumn{2}{|c|}{ Calibration set } & \multicolumn{3}{|c|}{ Prediction set } \\
\hline & & $R^{2}$ & RMSE & $R^{2}$ & RMSE & $R P D$ \\
\hline $\begin{array}{l}\text { Ash } \\
\text { (wt.\%) }\end{array}$ & 5 & 0.88 & 1.2 & 0.76 & 1.7 & 2.06 \\
\hline $\begin{array}{l}\text { VM } \\
\text { (wt.\%) }\end{array}$ & 5 & 0.89 & 2.1 & 0.79 & 3.0 & 2.20 \\
\hline $\begin{array}{l}\text { FC } \\
\text { (wt. \%) }\end{array}$ & 4 & 0.88 & 1.8 & 0.85 & 2.1 & 2.71 \\
\hline $\begin{array}{l}\mathrm{CV} \\
(\mathrm{MJ} / \mathrm{kg})\end{array}$ & 4 & 0.84 & 0.52 & 0.82 & 0.54 & 2.51 \\
\hline
\end{tabular}

Similarly, the PLSR models calibrating the NIR range of $780-1000 \mathrm{~nm}$ to biochar energy properties perform differently (Table 3 ). Although the PLSR model for ash content obtains slightly better performance with $R^{2}$ of 0.93 , and $R M S E$ of $0.9 \%$ for calibration, it does not improve prediction performance. The similar results can be found for fixed carbon content and calorific value. The only improvement was achieved for the PLSR model developed for biochar calorific value. It produces similar performance with $R^{2}$ of $0.88, R M S E$ of $2.3 \%$ for calibration, and $R^{2}$ of $0.85, R M S E$ of $2.6 \%$, and $R P D$ of 2.54 for prediction with only 2 latent variables for PLSR model. 
Table 3. Performance of PLSR models developed for 780$1000 \mathrm{~nm}$ spectra

\begin{tabular}{|c|c|c|c|c|c|c|}
\hline \multirow{2}{*}{$\begin{array}{l}\text { Biochar } \\
\text { energy } \\
\text { property }\end{array}$} & \multirow{2}{*}{$\begin{array}{l}\text { PLSR } \\
\text { LVs }\end{array}$} & \multicolumn{2}{|c|}{ Calibration set } & \multicolumn{3}{|c|}{ Prediction set } \\
\hline & & $R^{2}$ & RMSE & $R^{2}$ & RMSE & $R P D$ \\
\hline $\begin{array}{l}\text { Ash } \\
\text { (wt.\%) }\end{array}$ & 5 & 0.93 & 0.9 & 0.76 & 1.7 & 2.06 \\
\hline $\begin{array}{l}\text { VM } \\
\text { (wt.\%) }\end{array}$ & 2 & 0.88 & 2.3 & 0.85 & 2.6 & 2.54 \\
\hline $\begin{array}{l}\mathrm{FC} \\
\text { (wt.\%) }\end{array}$ & 4 & 0.89 & 1.7 & 0.84 & 2.2 & 2.59 \\
\hline $\begin{array}{l}\mathrm{CV} \\
(\mathrm{MJ} / \mathrm{kg})\end{array}$ & 4 & 0.80 & 0.56 & 0.68 & 0.75 & 1.81 \\
\hline
\end{tabular}

\subsection{Discussion}

Although we did not exploit the issue of how different charring temperatures make influences on the molecular structures of biochar, published reports may support us some useful knowledge on it. For examples, Peng et al. revealed by scanning electron microscopy(SEM) that with increasing temperature, biochar particles became smaller and retained less original cell structure[10]. Besides, Fourier transform infrared spectra of biochar derived from rice straw, pitch pine and wood showed that charring temperature alters the functional group of biochar, indicating a weaker adsorption intensity of $\mathrm{O}, \mathrm{H}$ and aliphatic $\mathrm{C}$ but stronger adsorption intensity of aromatic $\mathrm{C}$ with charring temperature[11,12]. Putun et al. reported that degradation of hemicelluloses and cellulose takes place at $200-300^{\circ} \mathrm{C}$ and $300-400^{\circ} \mathrm{C}$, respectively, while lignin degradation takes place at $200-700^{\circ} \mathrm{C}[13]$. $\mathrm{Kim}$ et al. found that formation of highly ordered aromatic structure of biochar begins at $400^{\circ} \mathrm{C}[11]$. As the chemical, physical and morphological changes of biochar affected by charring temperature would result in spectral changes of molecular vibration, spectroscopic analysis should be a useful tool for biochar energy quality monitoring, although more efforts must be conducted for further investigation.

\section{Conclusions}

In the study, vis-NIR reflectance spectra with wavelengths from 400 to $1000 \mathrm{~nm}$ were calibrated to the ash, volatile matter, fixed carbon content and calorific value of three types of biochar samples produced at different pyolysis temperatures.

Conclusions can be drawn as follows.

(1) Biochar energy quality can be predicted successfully by PLSR models developed or the 400$1000 \mathrm{~nm}$ reflectance spectra. In our case, PLSR models developed for BOC-transformed spectra achieved good prediction accuracy with $R^{2}$ of $0.85-0.87$ and $R P D$ of 2.61-2.85 for ash, volatile matter and fixed carbon content, and $R^{2}$ of 0.80 and $R P D$ of 2.27 for calorific value.

(2) The PLSR models calibrated for different wavelengths range present different prediction performance. In our case, the models developed for ash, volatile matter and fixed carbon content based on vis-NIR range of 400-1000nm achieve higher values of $R^{2}$ and $R P D$ for prediction compared with those based on visible range of $400-780 \mathrm{~nm}$ or NIR range of $780-1000 \mathrm{~nm}$. However, the PLSR model developed for biochar calorific value based on visible range of 400-780nm performs better than other two wavelength ranges. It may indicate that biochar natural colors have some relationship with biochar enengy quality.

(3) Biochar energy quality can be rapidly measured by a 400-1000nm spectrometer with acceptable prediction. Although a spectrometer with wider wavelengths range, for examples, of 350-2500nm, may produce better prediction result with higher accuracy, it is usually much more expensive. In our case, a USB4000 spectrometer could be fabricated as a low-cost tool for predicting biochar energy quality in practice.

\section{Acknowledgement}

This work was supported by research funds of China Postdoctoral Science Foundation (No.2013M540499), Zhejiang Provincial Postdoctoral Science Foundation of Year 2013, and Zhejiang Provincial Natural Science Foundation (No. LY13F010008).

\section{References}

1. J. Lehmann, Front. Ecol. Environ 5,7(2007)

2. M.A. Sanderson, F. Agblevor, M. Collins, D.K. Johnson, Biomass Bioenerg 11,6(1996)

3. N. Labbé, S.-H. Lee, H.-W. Cho, M.K. Jeong, N. André, Bioresour. Technol 99,8(2008)

4. G.G. Allison, C. Morris, E. Hodgson, J. Jones, M. Kubacki, T. Barraclough, N. Yates, I. Shield, A.V. Bridgwater, I.S. Donnison, Bioresour. Technol 100,6(2009)

5. K. Nkansah, B. Dawson-Andoh, J. Slahor, Bioresour. Technol 101,7(2010)

6. C.C. Fagan, C.D. Everard, K. McDonnell, Bioresour. Technol 102,7(2015)

7. H. Yang, B. Kuang, A.M. Mouazen, Eur. J. Soil Sci 63,11(2012)

8. H. Yang, A.M. Mouazen, Infrared Spectroscopy-Life and Biomedical Sciences (Intech Press 2012)

9. H. Yang, B. Kuang, A.M. Mouazen, Appl. Spectrosc $65,8(2011)$

10. X. Peng, L.L. Ye, C.H. Wang, H. Zhou, B. Sun, Soil Tillage Res 112,8(2011)

11. K.H. Kim, J.-Y. Kim, T.-S. Cho, J.W. Choi, Bioresour. Technol 118,5(2012)

12. M. Keiluweit, P.S. Nico, M.G. Johnson, M. Kleber, Environ. Sci. Technol 44,7(2010)

13. E. Putun, B.B. Uzun, A.E. Putun, J. Anal. Appl. Pyrolysis 79,7(2007) 